\title{
OS CÍRCULOS DE CULTURA EM GOIÂNIA: MEMÓRIAS DA CONTRIBUIÇÃO FREIREANA
}

\author{
Maria Margarida MACHADO \\ Universidade Federal de Goiás (UFG), Goiânia, Goiás, Brasil \\ CLÁUdia Borges Costa \\ Rede Municipal de Educação de Goiânia, Goiás, Brasil
}

\begin{abstract}
Resumo: O artigo apresenta a trajetória histórica dos Círculos de Cultura desenvolvidos na década de 1990 pela Secretaria Municipal de Educação (SME) de Goiânia-GO a partir das contribuições de Paulo Freire. Os estudos resultaram de pesquisa bibliográfica, partindo das obras de Paulo Freire e de outros que versam sobre sua vida e obra, para compreensão da trajetória dos Círculos de Cultura. Foram ainda analisadas dissertações e artigos sobre a experiência de educação de adultos na secretaria. Por fim, por meio da pesquisa documental, foi possível acessar e analisar fôlder e relatórios em cadernos de campo desse projeto de alfabetização. As reflexões indicam que os Círculos de Cultura se constituíram como importante recurso político-pedagógico para alfabetização, revelando-se como espaço alternativo de diálogo sobre a vida e inserção dos alfabetizandos na comunidade.
\end{abstract}

Palavras-chave: Círculos de Cultura. Paulo Freire. Alfabetização de Adultos em Goiânia. Memória e História.

\section{Primeiras palavras}

"a aplicação à história dos dados da filosofia, da ciência, da experiência individual e coletiva tende a introduzir, junto destes quadros mensuráveis do tempo histórico, a noção de duração, de tempo vivido, de tempos múltiplos e relativos, de tempos subjetivos ou simbólicos. O tempo histórico encontra, num nível muito sofisticado, o velho tempo da memória, que atravessa a história e a alimenta".

(JACQUES LE GOFF, 1990)

Dentre as várias reflexões advindas do ensejo em produzir este artigo, é preciso dizer, inicialmente, que o tempo presente nos envolve numa mistura de sentimentos de angústia e ansiedade. São mais de três mil mortes ao dia no país pela Pandemia de Covid-19, filas de contaminados à espera de vagas nos hospitais, tantas outras filas dentro dos hospitais para acesso à Unidade de Terapia Intensiva, além da chegada lenta das vacinas. Em meio a esse conflito, as memórias das vidas que se foram marcam o presente, seguem, inclusive, conosco a memória de tantas vidas compartilhadas em defesa do acesso à educação e à cultura dos empobrecidos dessa sociedade, como a de Maria Emilia de Castro Rodrigues, que seria uma das autoras deste artigo, se não tivesse perdido a vida, no dia 8 de março de 2021, para a Covid19. Iniciamos esta reflexão 
dedicando a ela este gesto de fazer memória daqueles que lutaram e lutam pelo direito de aprender e ensinar.

A partir deste tempo presente tão caótico, insistimos em pensar os tempos vividos, ressaltando experiências de Paulo Freire no campo da educação de adultos, revelando como elas foram fundamentais para inspirar o setor educacional em gestões de governos democráticos populares. Nesse sentido, o artigo busca fazer memória dos Círculos de Cultura que, atravessando tempos e espaços, compuseram a história da educação popular no Brasil, ganhando outros países e continentes, permanecendo viva em tantas outras experiências até os dias de hoje.

A reflexão estabeleceu diálogo entre as experiências dos Círculos de Cultura vivenciadas por Paulo Freire, no contexto da década de 1960, em diálogo com o poder público local e nacional, além de suas influências nos Círculos de Cultura desenvolvidos na cidade de Goiânia-GO, nos primeiros anos da década de 1990. A Prefeitura de Goiânia, a partir de 1993, foi governada pelo Partido dos Trabalhadores (PT) e retomou princípios da educação popular para nortear as ações desenvolvidas pela Secretaria Municipal de Educação (SME) voltadas para a educação de adultos.

Os estudos aqui apresentados resultaram de pesquisa qualitativa de tipo descritiva, a partir de fontes bibliográficas e documentais. A bibliografia de autoria de Paulo Freire, ou de autores que versam sobre sua vida e obra, auxiliou na reconstituição de sua trajetória de experiência na consolidação dos Círculos de Cultura como recurso político-pedagógico nos processos de alfabetização. Ainda, de caráter bibliográfico, foram analisados dissertações de mestrado e artigos que contribuíram para a compreensão da experiência de educação de adultos na SME de Goiânia. Por fim, por meio da pesquisa documental, foi possível acessar e analisar fôlder, relatórios em cadernos de campo (fontes localizadas no acervo da SME), produzidos ao longo da experiência dessa gestão do PT em Goiânia no período de 1993 a 1996.

Para a exposição das reflexões produzidas pelo estudo, o artigo parte, inicialmente, da vida e do pensamento de Paulo Freire, no contexto histórico brasileiro, sobretudo no período dos Círculos de Cultura na década de 1960. A partir da interpretação de Brandão (2017, p. 70), quando afirma que: "Anos mais tarde a tradição consolidada dos círculos de cultura foi bastante diferenciada e estendida às mais diversas situações educativas, dentro e fora das escolas, dentro e fora das salas de aula". Portanto, apresenta-se, a seguir, a experiência de Goiânia.

\section{PAULO FREIRE: VIDA, PENSAMENTO E O CONTEXTO HISTÓRICO BRASILEIRO}

O pensamento de Paulo Freire não pode ser concebido desvinculado do contexto histórico e cultural do Brasil. A sociedade brasileira, ao longo de sua história, vivencia as disputas e os conflitos inerentes ao sistema capitalista. As diretrizes da economia brasileira, salvo exceções, sempre se pautaram pela busca do desenvolvimento econômico, condicionado à manutenção das desigualdades sociais e à submissão às pressões externas. Nas palavras de Ana Maria de Araújo Freire: 
MACHADO, M. M.; COSTA, C. B.

A vida e a obra de Paulo Freire confundem-se, pois não escreveu sobre coisas abstratas ou distantes; que ouviu falar. Escreveu sobre o óbvio, o cotidiano, sobre aquilo que se via (que ele via), que se observava (que ele observava), que se escutava (que ele escutava) e o que se sentia (o que ele sentia) todos os dias (FREIRE, 2001, p. 3).

No fim da década de 1950 e início da década de 1960, embora o cenário agrárioexportador se abrisse para economia industrial, a realidade brasileira gritava pela profunda desigualdade entre a população empobrecida, presente nas diversas regiões do país. O censo de 1960 revelava os altos índices do analfabetismo entre a população de 15 anos e mais, correspondendo a $39,6 \%$ da população brasileira. A região Nordeste vivia essa desigualdade com altíssimos níveis de pobreza, com 59\% de pessoas com 15 anos e mais não alfabetizadas, segundo dados do IBGE (BRASIL, 1960).

Esse contexto brasileiro, sobretudo nordestino, na visão de Paulo Freire, revelava o domínio do silêncio, diante da sociedade cerrada em uma hierarquia, que buscava conter a reflexão, participação e construção de outra realidade, na qual a população se constituísse como sujeito histórico. Paulo Freire (2005), trabalhando com alfabetização de adultos, argumentava que o objetivo dessa educação deveria ser a inserção na dinâmica de uma construção societária, que só é possível por intermédio da consciência e organização das massas populares. Segundo Brandão (2017), essa perspectiva freireana se difunde em diversos movimentos:

Vários movimentos de cultura popular retomam procedimentos de dinâmica de grupos. Juntamente com uma crítica ética e, sobretudo, política, daquilo a que Paulo Freire deu o nome de educação bancária, por oposição a uma educação libertadora, surgem e se difundem práticas de ensinar-e-aprender fundadas na horizontalidade das interações pedagógicas, no diálogo e na vivência da aprendizagem como um processo ativo e partilhado de construção do saber (p. 69).

A efervescência de várias experiências em municípios e movimentos de cultura, os Centros Populares de Cultura (CPC) da União Nacional dos Estudantes (UNE) levavam o teatro ao povo. Os Movimentos de Cultura Popular (MCP) e o Movimento de Educação de Base (MEB) promoveram alfabetização de adultos de cunho político e pedagógico alinhada à proposta de Paulo Freire (BRANDÃO, 2001). Esses movimentos marcaram o período do início dos anos de 1960, que Freire tratará em suas reflexões no exílio, como uma sociedade em transição. Eram as primeiras experiências de uma educação libertadora, com ampla participação dos movimentos sociais no âmbito da alfabetização de adultos.

Esse processo foi marcado por uma concepção de alfabetização, que, segundo Paulo Freire (1967), não dizia respeito somente à leitura e escrita, mas à condição da capacidade de reflexão a partir da conscientização. A principal estratégia políticopedagógica eram os círculos de cultura, desenvolvidos nos espaços em que fosse possível organizar pessoas, em uma roda aberta ao diálogo que possibilitava a ação de compartilhar ideias e conhecimentos. A partilha entre educandos e educadores selava um espaço de coparticipação, em que a produção do conhecimento era recíproca. Nas palavras de Freire $(1967$, p. 3):

Inter-Ação, Goiânia, v. 46, n. ed.especial, p. 1242-1257, set. 2021. Disponível em: <http://dx.doi.org/10.5216/ia.v46ied.especial.68469>. 


\begin{abstract}
A visão da liberdade tem nesta pedagogia uma posição de relevo. É a matriz que atribui sentido a uma prática educativa que só pode alcançar efetividade e eficácia na medida da participação livre e crítica dos educandos. É um dos princípios essenciais para a estruturação do círculo de cultura, unidade de ensino que substitui a "escola", autoritária por estrutura e tradição. Busca-se no círculo de cultura, peça fundamental no movimento de educação popular, reunir um coordenador a algumas dezenas de homens do povo no trabalho comum pela conquista da linguagem. O coordenador, quase sempre um jovem, sabe que não exerce as funções de "professor" e que o diálogo é condição essencial de sua tarefa, "a de coordenar, jamais influir ou impor".
\end{abstract}

A vida, a prática, o trabalho e o contexto dos educandos eram considerados pontos de partida da proposta educativa. A compreensão crítica abria possibilidade para o reconhecimento de cada um como sujeito histórico e, portanto, construtor de sua história e da história da sociedade. A dinâmica do processo de alfabetização era mediada em cada círculo de cultura por temáticas abordadas pela comunidade, por meio do diálogo. Não havia a cartilha pronta, pois a abordagem desta trazia temas afastados da realidade dos educandos e impedia que eles fossem autores de seu processo de construção do conhecimento.

Depois do tema, a constituição da problematização apontaria o caminho no processo da aprendizagem. Tanto educadores como educandos pensavam e elaboravam coletivamente o material com o qual trabalhariam, dessa forma, a perspectiva da participação era constituída como fundamento nos conhecimentos construídos. Os círculos de cultura contavam com o conhecimento prévio do educador, que estava inserido na comunidade ou tinha grande conhecimento da realidade daquela comunidade.

O diálogo era profícuo e necessário para pesquisa do universo vocabular ou temático dos educandos. Desse universo temático, eram retiradas as palavras geradoras, que definiam a confecção do material de estudos a serem utilizados no processo formativo, assim, todo o material produzido tinha a identidade daquele círculo de cultura. Nessa perspectiva, o olhar e a reflexão da realidade social, leitura do mundo, seguida da leitura da palavra, traduziam a possibilidade da recriação de cada realidade particular.

Conforme Paludo (2017, p. 265), a proposição, realizada e vivida por Paulo Freire, provocava três momentos centrais:

a leitura da realidade (investigação), que deve ser codificada em Temas ou Palavras Geradoras; a descodificação (oral e escrita), que requer a problematização para a ampliação da compreensão crítica das "situações limites"; e a síntese cultural, como a possibilidade de organização da nova compreensão da realidade e da proposição da ação em direção a construção dos "inéditos-viáveis", da transformação. 
MACHADO, M. M.; COSTA, C. B.

A concepção de educação proposta por Paulo Freire parte de sua vivência com o povo pobre e sofrido do Brasil, principalmente da região nordeste do país, no entanto suas ideias transcenderam um tempo histórico e geográfico e ganharam o mundo. Mantendo a defesa da especificidade do conhecimento filosófico da práxis educacional, pautado no saber das classes populares como instrumento de transformação social, Freire passa a ser reconhecido mundialmente como andarilho da esperança. Em Pedagogia da autonomia (2005), ele reafirma, como um dos pressupostos básicos, que o homem é um ser inacabado. Daí que a educação exige a consciência do inacabado, da incompletude, para então buscar-se como sujeito que se integra no mundo, além de refletir sobre o seu tempo e espaço e cria condições para intervir em seu contexto e transformá-lo.

Em 18 de janeiro de 1963, Paulo Freire fez a aula inaugural da experiência de alfabetização de adultos em Angicos, fato que ganhou repercussão nacional e internacional. Conforme afirma Lyra (1996, p. 14), essa cidade recebeu, nesse período, diversos olhares, desde estudiosos da educação a "jornalistas não somente dos principais meios de comunicação do Brasil, como do exterior. Para lá se deslocaram, por exemplo, representantes do New York Times, do Time Magazine, do Herald Tribune, do Sunday Times, do United e da Associated Press, do Le Monde". A pequena cidade do sertão do Rio Grande do Norte tornou-se palco emblemático de uma experiência de Círculo de Cultura.

Além de desenvolver o aprendizado da leitura e escrita, a politização era a marca da experiência de Freire, que passou a coordenar o Programa Nacional de Alfabetização, a convite do então presidente João Goulart. Os Círculos de Cultura começam a se espalhar pelo Brasil, razão pela qual, com o golpe militar de 1964, Freire passou a ser perseguido pelo regime militar, sob a acusação de que seu "método de alfabetização" representava uma ameaça à "ordem" do país. Foi preso e depois exilado, primeiro no Chile, onde encontrou um clima social político favorável ao desenvolvimento de suas ideias. Freire (1994) descreve sua chegada no Chile, poucos dias depois da posse do governo democrático cristão de Eduardo Frey: "Havia um clima de euforia nas ruas de Santiago. Era como se tivesse ocorrido uma profunda, radical, substantiva transformação na sociedade" (FREIRE, 1994, p. 36).

Durante cinco anos, Paulo Freire (2005) trabalhou com programas de educação de adultos no Instituto Chileno para Reforma Agrária. No Chile, retomou sua tese, que resultou em seu primeiro livro: Educação como prática da liberdade. Freire (1967) reafirma, nesses escritos, a sua ideia de que nenhum ser humano pode prescindir de sua existência no mundo como sujeito histórico. É nesse país também que Paulo Freire (2005) escreveu sua principal obra Pedagogia do oprimido, a partir de suas vivências nos Círculos de Cultura como lugares de formação para a liberdade. Freire (1967) tinha clareza de que partir dos saberes populares indicava o reconhecimento do senso comum e da "cultura do silêncio", que precisavam ser superados. Em Pedagogia do oprimido (2005), aprofundando sobre a concepção bancária da educação, que impõe a visão de homem e mundo apartados, ele afirma:

Homens espectadores e não recriadores do mundo [...] como algo especializado neles [homens] e não aos homens como 'corpos conscientes' [...] como se fosse alguma seção 'dentro' dos homens, 
mecanicistamente compartimentada, passivamente aberta ao mundo que a irá "enchendo" de realidade (FREIRE, 2005, p. 72).

Assim, a consciência não consegue tomar a realidade e pensá-la de forma crítica. Para que isso ocorra, é necessário enfrentamento e superação da realidade por meio da práxis pedagógica, que tem como ponto de partida a pesquisa do universo vocabular do educando, sistematizada por intermédio de planejamento, de estudos teóricos e de novas pesquisas que possam problematizar e desvelar, de forma crítica, o contexto em que cada sujeito está inserido.

Freire (2005) defendia que todas as pessoas, sobretudo as mais pobres, poderiam, a partir da educação, conquistar a consciência crítica e política, e esse era o primeiro passo dos oprimidos em direção à emancipação e transformação da sociedade, embora não pudesse ser considerado como o único. Essa educação crítica dos homens oprimidos lhes permitiria adquirir e produzir conhecimento, forjar uma consciência crítica e política para lutar pela transformação individual e coletiva.

Essa concepção de educação emancipatória sofrerá com os atos deliberados do Regime Militar, de punição e cerceamento das liberdades individuais e coletivas por mais de vinte anos. A tentativa foi de silenciamento das lideranças que, como Freire e muitos alfabetizadores populares, foram processados e exilados, mas esse objetivo não foi alcançado. As reflexões de Freire, iniciadas no Brasil nos anos de 1960, se espalharam pela América Latina, América do Norte, Europa e África.

Quando o país inicia o processo de reabertura política, a partir do final da década de 1970, a volta dos exilados vai marcar a retomada dessas discussões sobre educação na perspectiva freireana. As experiências mais significativas serão implementadas pelos movimentos sindicais e populares, a partir da década de 1980, e podem também ser identificadas nas administrações municipais assumidas por partidos do campo democrático popular (FREIRE, 1991), a partir do final dos anos 1980 e início dos anos 1990. A experiência de Paulo Freire, como gestor municipal de educação em São Paulo, ocorrerá nesse contexto, entre os anos de 1989 e 1991. Dela, nasce o Movimento de Alfabetização (MOVA), como retomada das experiências dos Círculos de Cultura, que irá se espalhar por vários municípios do país. É nesse contexto que se situa a experiência dos Círculos de Cultura como o caso de Goiânia.

\section{OS CÍRCULOS DE CULTURA EM GOIÂNIA-GO}

Goiânia, capital do estado de Goiás, na década de 1990, inaugura, em sua constituição política no poder, uma coligação partidária encabeçada pelo Partido dos Trabalhadores (PT). A gestão 1993/1996 vivenciou a complexidade advinda da própria articulação da coligação, além da dificuldade no processo de gerenciar a prefeitura da capital, a partir de um projeto democrático popular, cujo objetivo propalado era contar com a participação da população para governar Goiânia. No âmbito da educação, o ensejo para participação das escolas na construção do plano de ação da Secretaria Municipal de Educação (SME) foi essencial para marcar uma nova proposta de gestão, em oposição aos 
MACHADO, M. M.; COSTA, C. B.

dez anos do Partido do Movimento Democrático Brasileiro (PMDB) à frente da prefeitura da capital de Goiás.

Conforme Avelar (2017, p. 64), a gestão do PT vivenciou dificuldades na permanência do grupo gestor da SME, assim, a secretaria passou pela mudança de "três secretários da educação: Professora Mindé Badauy de Menezes (janeiro/1993 a dezembro/1994); Professor Athos Magno (dezembro/1994 a setembro/1995) e Professora Vera Barêa (setembro/1995 a dezembro/1996)". As diversas pesquisas de mestrado acerca desse período, disponíveis em acervo digital do Fórum Goiano de Educação de Jovens e Adultos (2019), atestam que a tentativa de imprimir um caráter mais democrático na política educacional teria ocorrido, principalmente, na gestão da secretária Mindé, assegurando à Educação de Jovens e Adultos (EJA) ações prioritárias, sobretudo no âmbito da alfabetização de adolescentes, jovens, adultos e idosos.

Dentre outros projetos desenvolvidos nesse período, a busca pela proximidade com a educação popular possibilitou a retomada da experiência freireana dos Círculos de Cultura. Os princípios da educação popular foram retomados com o propósito de trazer reflexões sobre a educação de jovens e adultos, pois Goiânia apresentava uma grande parcela da população sem alfabetização. Conforme Avelar (2017, p. 84), “Em 1991, segundo dados do IBGE, o índice de analfabetismo em pessoas com mais de 10 anos era de mais de $8 \%$, o que representava um número superior a 60.000 pessoas não alfabetizadas nesta faixa etária".

A experiência dos Círculos de Cultura para alfabetização de jovens, adultos e idosos em Goiânia teve início em agosto de 1993, sob a coordenação da SME, que fez seu lançamento público na Câmara de Vereadores e distribuiu pela cidade um fôlder para explicar do que se tratava o Projeto de Alfabetização de Adultos.

Figura 1 - Imagem de capa do fôlder

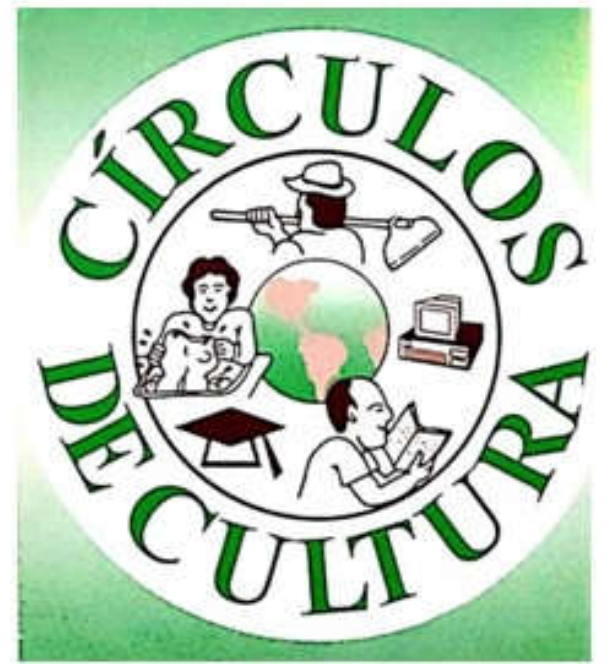

Fonte: Fôlder de divulgação do Projeto de Alfabetização de Adultos. Goiânia-GO/SME. 
A SME objetivava com essa experiência chegar às pessoas que tinham dificuldades ou resistência de procurar as escolas e, assim, contribuir para cultivar a vontade de buscar os estudos. A perspectiva do processo de alfabetização deveria servir para aumentar a autoestima do público específico. O material divulgado pela SME, em 1993, registrava o significado do projeto, objetivos, funcionamento e parcerias.

Figura 2 - O que é o projeto

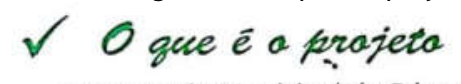

A Secretaria Municipal da Educação de Goiânia, tendo em vista uma de suas diretrizes prioritárias: a democratização do acesso e da permanência de todos na escola, tem atuado, em parceria com entidades governamentais e não-governamentais, na Alfabetização de Adultos.

O Projeto é uma retomada do processo de leitura e escrita do mundo e do código escrito, tendo como eixo a realidade do adulto trabalhador e suas expectativas em relação a melhores condiçōes de vida.

Fonte: Fôlder de divulgação do Projeto de Alfabetização de Adultos. Goiânia-GO/SME

O projeto era executado por meio de convênios entre a SME e diversas entidades parceiras, que organizavam a estrutura física para o funcionamento dos Círculos de Cultura e indicavam os alfabetizadores populares. De acordo com os relatórios da experiência, acessados por esta pesquisa, pode-se constatar que os locais onde funcionaram os Círculos de Cultura eram salas cedidas por igrejas, associações de moradores, sindicatos, empresas e, até mesmo, em garagens de residências. Os alfabetizadores populares, por sua vez, eram pessoas da própria comunidade local, que, tendo concluído a Educação Básica, recebiam formação semanal de profissionais da SME e professores da Universidade Federal de Goiás e Universidade Católica de Goiás sobre os princípios e a metodologia de alfabetização a ser utilizada. Cabia à $\mathrm{SME}$, ainda, a responsabilidade de disponibilizar o material necessário para a produção dos recursos didáticos a serem utilizados nos Círculos de Cultura pelos alfabetizadores.

No fôlder de divulgação, constam como parceiros: CNBB/MEB/MEC, Sindicato dos Trabalhadores do Lar (SINTRADEGO), Sindicato dos Trabalhadores Urbanitários de Goiás (STIUEG), Instituto da Irmãs Missionárias de Cristo, Comunidade Bahai, Sociedade Beneficente Maria Benta (SOBEM), Comunidades da igreja Católica, Sub-Prefeitura de Abadia de Goiás, Companhia Municipal de Urbanização de Goiânia (COMURG) e Fundação Municipal de Desenvolvimento Comunitário (FUMDEC). 
MACHADO, M. M.; COSTA, C. B.

Figura 3 - O que é parceria

\section{$\checkmark$ que è parceria}

A experiência de parceria da $S M E$, iniciou com o MEB, Movimento de Educação de Base, financiando os monitores. Logo percebemos que para que o trabalho refletisse na realidade dos bairros onde atuariamos, era necessária a parceria com as entidades destes bairros. Atualmente, contamos com dezenas de parceiros que atuam, conjuntamente, na avaliação dos alcances do projeto e seus possiveis desdobramentos.

Fonte: Fôlder de divulgação do Projeto de Alfabetização de Adultos. Goiânia-GO/SME.

As ações de alfabetização ocorriam em três dias semanais, num período de duas horas cada encontro. As definições de horário, local e dias de funcionamento eram feitas a partir do diálogo de alfabetizandos e alfabetizadores, numa sintonia com os Círculos de Cultura vivenciados por Paulo Freire, que primava nas ações educativas pelo "respeito à liberdade dos educandos - que nunca são chamados de analfabetos, mas de alfabetizandos [...] busca-se um máximo de interferência do povo na estrutura do programa" (FREIRE, 1967, p. 11).

As parcerias constituídas para desenvolver os Círculos de Cultura possibilitaram espalhar pela cidade os espaços de alfabetização. Os diversos bairros abriram lugares de acolhida para a alfabetização de adultos no Município de Goiânia e em município da região Metropolitana, Aparecida de Goiânia. A dinâmica da organização dos grupos dependia da busca constante dos educandos, por isso,

\footnotetext{
onde os educandos jovens, adultos e idosos estavam, à semelhança do que os movimentos de educação popular o faziam, os Círculos de Cultura eram realizados em vários espaços (igrejas, associações de moradores, Centros de Convivência de Idosos). Esta era uma forma de atrair e mobilizar os educandos a voltarem a estudar, pois facilitava o acesso do grupo, além de aumentar a inserção no lócus destes sujeitos e promover uma maior aproximação com sua realidade (AVELAR, 2017, p. 83).
}

O caráter da mobilização, no ano de 1993, tinha a perspectiva do alcance à população historicamente excluída da escola, para o retorno ao ambiente dos estudos, o que já representava uma crítica à condição marginal da escola. Essa mobilização também questionava, nas palavras de Freire (1967, p. 24), a "tradicional situação de marginalidade em que se encontram as massas. Os homens do povo que tomaram parte nos Círculos de Cultura fazem-se cidadãos politicamente ativos ou, pelo menos, politicamente disponíveis para a participação democrática". 
Dentre os inúmeros registros nos cadernos dos coordenadores e alfabetizadores do projeto (denominados cadernos de registros), arquivados no acervo desta pesquisa, pode-se identificar relatos que demonstram um pouco da realidade vivenciada nesses Círculos de Cultura em Goiânia. No relato da primeira aula, datada de 16 de agosto de 1993, em um dos bairros, menciona-se o comparecimento de "11 alunos". Anexado a esse relato, encontra-se um documento que buscava conhecer e registrar o percurso dos estudos dos educandos, intitulado Levantamento para Alfabetização de Jovens e Adultos. Na frente de cada nome, escrito com a letra da educadora, é possível identificar um diagnóstico inicial sobre os educandos: "lê, escreve e faz continhas; assina o nome; mal assina o nome; faz conta de cabeça; lê pouco" (Caderno de Registros N. 1,1993, p. 3).

A partir ainda do registro no caderno, pode-se identificar a dinâmica do Círculo de Cultura vivenciada em oito passos, assim registrados:

\footnotetext{
Ficha auxiliar com dados pessoais e familiares; Diálogo dois a dois sobre temas pessoais; Apresentação recíproca das opiniões e informações; Projeto; Quartas-feiras -serão dias diferentes, só cultura; Leitura de material como: rótulos, caixas etc.; Escrita de palavras e números tirados dos materiais; Despedida muito cordial, com visível contentamento de todos (Caderno de Registro n. ${ }^{\circ}$ 1, 1993, p. 3).
}

Os dados pessoais e familiares dos registros foram delineando o perfil do grupo. Dos 11 educandos, cinco mulheres entre 26 e 72 anos e seis homens entre 19 e 58 anos. Todos(as) trabalhadores(as) na ativa ou desempregados. Nos dois passos seguintes, entre diálogo e apresentações, opiniões e informações sobre a realidade dos educandos, foi se revelando o desejo de "ler escrever e contar corretamente, desenvolver a conversa, assinar o nome completo, escrever carta, ler placas de ônibus" (Caderno de Registros N. ${ }^{\circ}$ 1, 1993, p. 3).

Esse Caderno de Registros também era utilizado pela coordenação do projeto para acompanhar as ações do Projeto de Alfabetização, como pode ser observado no relato que indica a existência de 12 Círculos de Cultura, espalhados pelos bairros de Goiânia, na primeira semana de execução, com um atendimento de 256 educandos (Caderno de Registros N.o 2, 1993, p.13). Os círculos de cultura se constituíram como espaço educativo onde educandos e educadores experienciaram o diálogo como instrumento coletivo e de ajuda mútua. O diálogo não era um mero instrumento metodológico, mas uma forma de partilha de saberes e possibilidade de construção, em conjunto, de conhecimento.

Ainda sobre a dinâmica proposta para os Círculos de Cultura, os registros indicam que "Quartas-feiras serão dias diferentes, só cultura" (Caderno de Registros N. ${ }^{\circ}$ 1, 1993, fl. 20). A dimensão da cultura propõe reflexões sobre os seres humanos como sujeitos de cultura. Sobre isso, Freire (2005) convida a pensar sobre os homens e mulheres por meio de sua ação no mundo, o que gera o domínio da cultura e da história. No Caderno de Registro no 1, o dia 01/09/1993, em um dos Círculos de Cultura, apresenta a quarta-cultural: "Demonstração de um Grupo de Capoeira do Bairro. 
MACHADO, M. M.; COSTA, C. B.

Resenha histórica sobre as origens e evolução da capoeira no Brasil, proferida pelo professor Assis vulgo Guerreiro, que dirige o grupo de Capoeira local" (Caderno de Registros N. 1,1993, p. 20).

No que concerne à preparação dos coordenadores e alfabetizadores do Projeto, na experiência de Goiânia, a formação deu-se de forma concomitante à abertura dos Círculos de Cultura. Um dos objetivos registrados no fôlder de divulgação da SME diz respeito a "Formar educadores populares que possam dar continuidade ao projeto na abertura de novos círculos" (Fôlder de divulgação do Projeto de Alfabetização de Adultos. Goiânia-GO/SME, 1993). Os relatos escritos datam do dia 02/08/1993 ao dia 13/08/1993 (Caderno de Registros N.o 2, 1993, p.1-11). Referidos relatos registram inúmeras técnicas, reflexões sobre as técnicas e as possibilidades de serem vivenciadas com os educandos muitas leituras de textos e artigos com definição de chaves de leituras, identidade, cultura, história de vida, reflexões sobre o trabalho com a matemática.

Essa prática de reflexões e envolvimento participativo dos educadores populares na formação constituiu o caráter da horizontalidade que depois era levada para os Círculos de Cultura com os educandos, que se sentiam pertencentes aos grupos de alfabetização. "O trabalho em equipe, o diálogo como criação de consensos entre iguais e diferentes" (BRANDÃO, 2017, p. 69) foi a tônica dos Círculos de Cultura na década de 1960 e foi largamente vivenciado na experiência de Goiânia.

Nessa perspectiva, por meio do diálogo respeitoso, se pesquisa e registra as palavras proferidas livremente nos primeiros encontros, palavras essas que fazem parte da vida do alfabetizando. Os vocábulos que integram a realidade dos educandos carregam significados legítimos de seu contexto social e caracterizam condições da existência dos educandos. No Caderno de Registro N. ${ }^{1}$, colado na página 1, consta uma ficha intitulada: "Seleção das Palavras-Geradoras do Círculo de Cultura - Critérios das Dificuldades Fonêmicas, as palavras foram, assim, registradas: CASA- SAÚDE- CHUVA ÔNIBUS - CAPOEIRA - RELIGIÃO- VIZINHO - FAMÍLIA - JOGO- ESCOLA- TELEVISÃOÁGUA - LIXO - TRABALHO - MÁQUINA - TERRA - ELEIÇÃO - ASSOCIAÇÃO" (Caderno de Registros N..$^{1}$, 1993, fl. 1). O registro da aula do dia 17/08/1993 apresenta todo o percurso do trabalho realizado a partir da palavra geradora CASA.

\begin{abstract}
Cada um [alfabetizandos] recebeu um pedaço do desenho e tínhamos que montar juntos para ver o que iria sair. Inicialmente, alguns ficaram sentados, depois pouco a pouco, todos foram se envolvendo na montagem até que saiu o desenho da CASA. Debate: a) O que formamos? b) Quem tem casa aqui? c) Todos no Brasil têm casa? d) O que precisaríamos fazer para que todos tivessem uma casa? Escrita: Pedimos que as pessoas que quisessem fossem ao quadro escrever a palavra. Vários foram e escreveram. [...] Pegamos novamente os materiais de leitura diversa e pedimos que alguém localizasse a palavra CASA (Caderno de Registros N. ${ }^{\circ}$ 1, 1993, p. 4).
\end{abstract}

O relato de outro grupo faz o mesmo caminho e acrescenta: "trabalhou em cima de palavras compostas foneticamente com as famílias de CA e SA" (Caderno de Registros N. ${ }^{1}$, 1993, p. 7). Com a palavra geradora CHUVA, os registros do dia 24/08/1993 iniciam com o informe de que o presidente da Associação de Moradores, o qual convidara a 
todos para a reunião do dia seguinte sobre o Projeto Goiânia Viva, "que previa a criação de Conselhos Populares Regionais, como mecanismo de descentralização e discussão permanente das ações do Poder Público Municipal" (FONSECA, 2010, p. 129). Em seguida, o relato traz o debate em torno da palavra geradora CHUVA, que possibilitou refletir sobre a realidade do bairro e todas as dificuldades vivenciadas, sobretudo no período da chuva, que emergia toda a falta de infraestrutura do bairro no período.

a) O que aconteceu nestes últimos dias que nos pegou de surpresa? b) Como acontece a chuva? c) Quais benefícios que a chuva traz? d) Quais problemas que enfrentamos com as chuvas? D) O que devemos fazer para evitar estes problemas? Decodificação da palavra (CHUVA): Cada albabetizando foi localizar em cartazes grandes de bancas de revista, os pedaços da família do $\mathrm{CHU}$ e do VA. Montamos o cartaz com o auxílio de todos e formamos algumas palavras (Caderno de Registros N.0 1, 1993, p. 12).

$\mathrm{Na}$ continuidade do relato, tem o registro dos grupos de alfabetizandos em movimento para construção de cartaz reivindicatório com as necessidades do bairro, além do chamamento para todos participarem da reunião do dia seguinte na Associação de Moradores: "Asfalto, esgoto, quadra de esporte, hospital, lote, horta para escola..." foram reivindicações registradas, que contou com a participação de dois grupos de alfabetizandos (Caderno de Registros N. ${ }^{\circ}$ 1, 1993, p. 12).

Os registros informam sobre vários momentos de avaliação dos processos de aprendizagem dos alfabetizandos nos Círculos de Cultura. Nos trechos destacados a seguir, do dia 30/11/1993, encontram-se alguns depoimentos individuais:

Alguma coisa eu já estou lendo, mais do que lia antes. Os números é que preciso saber mais. Meu sonho é desarmar a ler jornal, fazer carta, aprender a costurar. A amizade da gente é muito grande hoje. Eu não conhecia ninguém, agora tenho muitos amigos. Eu não via nenhuma letra no quadro, hoje já leio alguma coisa. Estou muito satisfeito. O meu sonho já vem de muito tempo: tirar carteira para dirigir caminhão. Muita coisa que eu não conhecia, agora já leio mais desembaraçado. Esse jeito explica mais. As pessoas aqui, uma ajuda o outro. Eu penso em tirar carteira de motorista para dirigir táxi (Caderno de Registros N.o 1, 1993, p. 37).

Os relatos chamam atenção para o significado da aprendizagem para cada um. Ainda que as dificuldades sejam reais, percebem o que foi alcançado e o quanto foi significativo para cada um, sobretudo no ressignificar dos sonhos. A possibilidade do encontro com o outro também foi de grande importância para os alfabetizandos, o que está em sintonia com as reflexões de Freire (2005, p. 93): “Neste lugar de encontro, não há ignorantes absolutos, nem sábios absolutos: há homens que, em comunhão, buscam saber mais".

Os Círculos de Culturas permaneceram funcionando até 1996 nesse projeto coordenado pela SME de Goiânia. Alguns registros expressam os desafios encontrados, 
as dificuldades com alguns grupos, sobretudo no que dizia respeito a: infraestrutura, como, por exemplo, pouca iluminação dentro de alguns espaços onde eram desenvolvidas as atividades; dificuldades com os alfabetizadores, quanto à compreensão da proposta metodológica, tendo em vista que a maioria não possuía formação em nível médio ou superior para ser professor; organização da documentação para o pagamento das bolsas que eles recebiam, já que os alfabetizadores não tinham um contrato de trabalho, mas assinavam um termo de voluntariado no Projeto; dentre outras.

Para além dessas dificuldades internas ao projeto, a descontinuidade na gestão da SME de Goiânia foi indicada como determinante para que os Círculos de Cultura tivessem cumprido papel um tanto efêmero na história da educação popular na cidade de Goiânia-GO. A mudança de três secretários de educação em um curto espaço de tempo, como já mencionado, contribuiu para o pouco avanço dos objetivos propostos para o Projeto de Alfabetização de Adultos, no início da gestão (MACHADO, 1997). Ainda assim, a memória dessa experiência atravessou a história da SME, principalmente da EJA nessa secretaria.

\section{CONSIDERAÇÕES FINAIS}

Retomando a epígrafe deste artigo, "o velho tempo da memória", no presente escrito, dois tempos de memória foram abordados para refletir sobre os Círculos de Cultura. O primeiro trouxe o marco dos Círculos de Cultura pensados e vivenciados por Paulo Freire, na década de 1960, e que se estendeu para outros países e continentes. A segunda memória abordou os grupos de Círculos de Cultura organizados na cidade de Goiânia-GO, nos primeiros anos da década de 1990, na contramão das inúmeras investidas das reformas neoliberais que foram implementadas na educação no Brasil nesse mesmo contexto. Os Círculos de Cultura, como espaço de encontro e aprendizagem, marcaram diversas experiências de alfabetização de adultos e dão testemunho da educação popular como instrumento de dimensão epistemológica, mas também como ação cultural para transformação das condições sociais dos alfabetizandos e das comunidades que estavam inseridos.

A vivência dos Círculos de Cultura em Goiânia teve o envolvimento de parceiros da educação e de agentes da cultura popular, o que contribuiu desde o financiamento de monitores até o desenvolvimento da formação dos educadores/alfabetizadores populares, que eram indicados pelas entidades parceiras. Para compor essa memória utilizamos a pesquisa documental e referências de pesquisas consolidadas em dissertações e documentos, que ainda estão sendo tratados e fazem parte do acervo da pesquisa sobre EJA em Goiânia e em Goiás.

Apesar do tempo curto dessa experiência constituída pela SME de Goiânia, os registros demonstram que ela se configurou como tentativa de espaço alternativo de diálogo e reflexão sobre a realidade de vida do adulto trabalhador, da sua família e da sociedade onde estavam inseridos. Quem sabe reinventar os Círculos de Cultura, nesses tempos difíceis do Século XXI, poderia se constituir numa experiência composta de aprendizagem, convivência respeitosa, cidadania e motivação humana. Uma alternativa para criar possíveis vínculos e aproximação com os mais de 11 milhões de pessoas não alfabetizadas nesse país, ou ainda, com os mais de 38 milhões que se encontram na 
condição de analfabetismo funcional (BRASIL, 2019), para reaverem seu direito constitucional à educação.

Artigo recebido em: 01/04/2021

Aprovado para publicação em: 29/06/2021

\section{THE CIRCLES OF CULTURE IN GOIÂNIA: MEMORIES OF FREIRE'S CONTRIBUTION}

ABSTRACT: The present article presents the historical pathway of the culture circles developed by the Cities Department of Education of Goiânia-GO in 1990s, aided by Paulo Freire's work. The bibliographical research needed to build the study used the author's work, as well as other previous studies about his papers, to better understand the trajectory of the culture circles. Thesis and articles on the experience of educating non-literate adults in the secretariat were also analyzed. Lastly, the documentary research accessed and analyzed files and reports in field notebooks of this literacy project. The reflections indicate that the culture circles were constituted as an important political-pedagogical resource for literacy, which proved to be an alternative space for dialogue about the life and the insertion of adult literacy learners in the community.

KEYWORDS: Culture Circles. Paulo Freire. Adult Literacy in Goiânia. Memory and History.

\section{LOS CÍRCULOS DE CULTURA EN GOIÂNIA: RECUERDOS DE LA CONTRIBUCIÓN DE FREIRE}

RESUMEN: El artículo presenta la trayectoria histórica del Círculo de Cultura desarrollado en la década de 1990 por el Departamento Municipal de Educación (SME) de Goiânia-GO, a partir de los aportes de Paulo Freire. Los estudios, resultado de la investigación bibliográfica, partieron de los trabajos de Paulo Freire y de otros que investigan sobre su vida y obra, para comprender la trayectoria de los Círculos de Cultura. También se analizaron disertaciones y artículos sobre la experiencia de la educación de adultos en la secretaría. Por último, la investigación documental accedió y analizó archivos y informes en los cuadernos de campo de este proyecto de alfabetización. Las reflexiones señalan que los Círculos de Cultura se constituyeron como un importante recurso político-pedagógico para la alfabetización, que resultó ser un espacio alternativo de diálogo sobre la vida y la inserción de adultos en el proceso de alfabetización en la comunidad.

PALABRAS CLAVES: Círculos de Cultura. Paulo Freire. Alfabetización de Adultos en Goiânia. Memoria e Historia. 


\section{REFERÊNCIAS}

AVELAR, G. M. M. F. O processo de constituição das propostas político-pedagógicas da educação de adolescentes, jovens e adultos na rede municipal de educação de Goiânia no período de 1993 a 2016. 2017. 250 f. Dissertação (Mestrado em Educação) Universidade Federal de Goiás, Goiânia, 2017. Disponível em: <http://forumeja.org.br/go/sites/forumeja.org.br.go/files/dissertacao_glauciaavelar.pdf >. Acesso em: 25 mar. 2021.

BRANDÃO, C. R. De Angicos a Ausentes: quarenta anos de educação popular. Porto Alegre: MOVA/RS/CORAG, 2001.

BRANDÃO, C. R. Círculo de Cultura. In: STRECK, D.; RENDIN, E.; ZITOTSKI, J. (org.). Dicionário Paulo Freire. Belo Horizonte: Autêntica, 2017. p. 69-70.

BRASIL. Instituto Brasileiro de Geografia e Estatística. Censo Demográfico de 1960. Disponível em: <shorturl.at/tCKRZ>. Acesso em 22/03/2021.

BRASIL. Instituto Brasileiro de Geografia e Estatística. Pesquisa Nacional por Amostra de Domicílios 2019. Disponível em: <https://educa.ibge.gov.br/jovens/conheca-obrasil/populacao/18317-educacao.html >. Acesso em: 22 mar. 2021.

FONSECA, J. F. R. O Orçamento Participativo e a Gestão Democrática de Goiânia. Revista Anhanguera, Goiânia, v.11, n.1, jan./dez., 2010, p.105-138. Disponível em: $<$ https://anhanguera.edu.br/wp-content/uploads/cap_06_2010.pdf $>$. Acesso em: 28 mar. 2021.

FREIRE, P. Educação como prática da liberdade. Rio de janeiro: Paz e Terra, 1967.

FREIRE, P. Conscientização: Teoria e Prática da Libertação - Uma Introdução ao Pensamento de Paulo Freire. São Paulo, Cortez \& Moraes. 1979. Disponível em: $<$ https://www.fpce.up.pt/ciie/sites/default/files/Paulo\%20Freire\%20\%20Conscientiza\%c3\%a7\%c3\%a3o_pp.5-19.pdf >. Acesso em: 25 mar. 2021.

FREIRE, P. Ação Cultural para a liberdade. Rio de Janeiro, Paz e Terra. 1981. 5 ed., 149 p. Disponível em: <shorturl.at/mvSU9 $>$. Acesso em: 25 mar. 2021.

FREIRE, P. Educação na Cidade. São Paulo: Cortez Editora, 1991.

FREIRE, P. Pedagogia da Esperança: um reencontro com a Pedagogia do Oprimido. Rio de Janeiro: Paz e Terra, 1994.

FREIRE, P. Pedagogia do Oprimido. 41a Edição. Rio de janeiro: Paz e Terra, 2005. 
Fórum Goiano de Educação de Jovens e Adultos. Acervo de acesso disponível em: <http://forumeja.org.br/go/node/1919 >. Acesso em: 25 mar. 2021.

LYRA, C. As quarenta horas de Angicos: uma experiência pioneira de educação. São Paulo: Cortez, 1996.

MACHADO, M. M. Política Educacional para Jovens e Adultos: A Experiência do PROJETO AJA (93/96) na Secretaria Municipal da Educação de Goiânia. 1997. 160 f. Dissertação (Mestrado em Educação Escolar Brasileira) - Universidade Federal de Goiás (UFG), Goiânia, 1997. Disponível em: <shorturl.at/rBKT1>. Acesso em: 25 mar. 2021.

PALUDO, C. Metodologia do trabalho popular. In: STRECK, D.; RENDIN, E.; ZITOTSKI, J. (org.). Dicionário Paulo Freire. Belo Horizonte: Autêntica, 2017. p. 264-265.

\section{Documentos dos Círculos de Cultura - Experiência Goiânia-GO:}

Caderno de Registros N.o 1, 1993-1996, fls. 1- 100.

Caderno de Registros N. ${ }^{2}$, 1993-1996, fls. 1-55.

Fôlder: Projeto de Alfabetização - Círculos de Cultura (Material de divulgação).

\footnotetext{
Maria Margarida Machado: Doutora em Educação pelo Programa de Pós-Graduação em Educação, História, Política e Sociedade da Pontifícia Universidade Católica de São Paulo. Professora Titular da Faculdade de Educação da Universidade Federal de Goiás. Coordenadora do Projeto Centro Memória Viva - Documentação e Referência em EJA, Educação Popular e Movimentos Sociais. Bolsista Produtividade CNPq.

Orcid: https://orcid.org/0000-0002-5036-4334

E-mail:mmm2404@ufg.br
}
Cláudia Borges Costa: Doutora em Educação pelo Programa de Pós-Graduação em Educação da Universidade de Brasília - UNB. Atualmente é Profissional da Educação Aposentada da Rede Municipal de Educação/RME de Goiânia-GO e Professora do Curso de Pedagogia na UNIALFA, membro do Grupo de Pesquisa do Centro Memória Viva- GO e do Núcleo de Pesquisas e Estudos em Educação e Formação de Trabalhadores (NUPEEFT) do IFG e atuante do Movimento Fórum Goiano de EJA.
Orcid: https://orcid.org/0000-0002-0378-3245
E-mail: cbc2111@smail.com

Este periódico utiliza a licença Creative Commons Attribution 3.0, para periódicos de acesso aberto (Open Archives Initiative - OAI). 